\title{
Faith in the Water God General Yang Si and the Construction of Its Sacred Field at Taoyuan
}

\author{
Dandan Zheng', Bing Zhao ${ }^{1,2, *}$ \\ ${ }^{1}$ School of Arts And Communication, China University of Geosciences, Wuhan, China \\ ${ }^{2}$ School of Urban Design, Wuhan University, Wuhan, China
}

\section{Email address:}

1027254503@qq.com (Bing Zhao)

${ }^{*}$ Corresponding author

\section{To cite this article:}

Dandan Zheng, Bing Zhao. Faith in the Water God General Yang Si and the Construction of Its Sacred Field at Taoyuan. Science Discovery. Vol. 7, No. 5, 2019, pp. 272-277. doi: 10.11648/j.sd.20190705.13

Received: July 8, 2019; Accepted: September 24, 2019; Published: September 27, 2019

\begin{abstract}
Sacred land experience is exclusive to the sacred space, with its unique geographical location, the spiritual beliefs of ethnic groups as the carrier, become a place of pilgrimage for people. In view of the increasingly serious problems such as floods, soil erosion and water pollution, we should respect rivers to advocate the harmonious coexistence of human and water. Through sacrificial activities, site selection, spatial pattern and symbolic system, this paper explains the future focus on the research and protection of historical space culture, revealing the close correlation between the construction of sacred sites and the planning of ecological environment protection.
\end{abstract}

Keywords: Water God, Belief, Holy Domain, Construction of Spatial Pattern, Ecological Environment

\section{桃源杨泗将军水神信仰及其圣域营造}

\author{
郑丹丹 ${ }^{1}$, 赵冰 $^{1,2^{*}}$ \\ ${ }^{1}$ 中国地质大学艺术与传媒学院, 武汉, 中国 \\ 2武汉大学城市设计学院, 武汉, 中国 \\ 邮箱 \\ 1027254503@qq.com(赵冰)
}

摘要: 圣域体验专属于神圣的空间领域, 以其独特的地理方位、族群的精神信仰为载体, 成为人们的朝圣之地。鉴于 当代洪涝、水土流失以及水质污染等问题越发严重的情况下，敬畏江河、来崇尚人与水和谐共生。本文通过祭祀活动、 圣域选址、空间格局及象征体系来阐释未来的重点在历史空间文化的研究与保护上, 揭示出圣域遗址的营造与生态环 境保护的规划上具有紧密的关联性。

关键词: 水神信仰, 圣域营造, 祭祀, 空间格局, 水环境

\section{1. 引言}

圣域营造, 是要研究圣域中所投射出来的思想信仰, 圣域不单单是自然景观所感受到的场所, 更是一个神圣教
化的空间, 赋予精神寄托的圣地。“自从亨・列斐伏尔提出 空间生产理论后, “空间就是社会”的论断成为一种共识, 空间生产理论也因此统一了“物质领域、精神领域以及社 会领域”,[1], 并开启了文化的空间转向和社会的空间研究 热点。[2]域营造也是一种空间的营造，“在建筑中，空间 
的形式意味着场所、路径和领域, 也就是, 人类环境的具 象结构。”[3]圣域营造是对神圣空间的营造研究; 是对道 教思想与当代社会关系的研究。

当今随着中华文化的复兴, 道的精神再次被人们所重 视, “道教是中国的本土宗教, 在其从先秦至当代的发展 过程中与其他宗教思想相互融合, 是一种与中国世俗社会 紧密结合的宗教。”[4]神庙的营造是道之精神的体现, 道 教的重要特点即“崇水”, “上善若水”, “水利万物而不争” 等, 透射出道教对人与自然、人与环境之间的和谐共生的 理念。“生态文明建设的终极目标是人与自然的和谐共生, 从而使人类社会真正可持续发展。”[5]水神庙圣域的保护 与水环境保护之间的关系是本篇文章研究的重点, 将道的 象征性及外化的空间结构形态, 通过今天的叠痕营造并展 现出来。本文以桃源水神杨泗将军信仰为参照对象, 试图 展现其圣域营造独特的空间概念、营造的象征系统及其建 筑存在的意义, 揭示出水神庙历史圣域是多种影响因素形 成的。“融合中国人心中的天人合一境界, 正如老子所说: “人法地、地法天、天法道, 道法自然”。[6]

\section{2. 水神信仰兴起的文化环境}

“水神信仰是渔民在生产生活过程中，形成朴实生态 的渔民文化。”[7]在古代社会, 人们临水而居, 靠水又畏 水, 在面对无法解释和应对的自然灾害面前, 水神信仰应 运而生, “水神的职能以平息水患、守护航道为主, 以祈 求风调雨顺为辅。”[8]

\section{1. 水神信仰与道教环境思想}

“在人类的生活中, 水是最大的因素, 人们认为天气 的转换是由于超自然的神的意志, 水的多葟也是由于神的 慈悲或是恶意, 农耕民族常把与他们生活有密切关系的水 或雨加以人格化而成为水神或雨神, 人类为了取悦神而有 祈祷与供牺的小神祭祀礼仪。”[9]“为道教提供了丰富养料 的原始自然宗教, 首推水崇拜。水崇拜以水的神秘力量、 各类水神为崇拜对象, 以水生万物、水神司雨水观念为基 本内涵, 以祈求降雨止雨和生殖繁衍仪式为主要表现形式, 是在农业中国延续时间最长、覆盖地域最广的原始自然宗 教之一。”[10]对水的崇拜是道教环境思想的重要组成部分, 明初堪與学家周景一所著《山洋指迷》云: “气者, 水之 母也; 水者, 气之子也。有气斯有水, 有水斯有气。气无 形而难见, 水有迹而可求。水来则气来, 水合则气止, 水 抱则气全, 水汇则气蓄。”[11]意思为得水为上, 可以以水 的形态、性情来判断事情的吉凶、人物的美丑等, 即中国 传统意义上的环境地理学。“道教重生, 其以“道法自然” 为原则, 以自然为师, 与自然相亲, 重视人与环境的关系, 善于利用环境中的一切有利因素、选择健全的自然生态系 统, 来实现天人合一、长生久视的目标。”[12]

关于水神信仰种类繁多、神邸众多、身居数职等特点。 谭徐明的《古代区域水神崇拜及其社会学价值》中谈到“根 据社会学功能水神崇拜可以分为自然之神与治水之神两 大类”, 自然之神例如雷公、龙蛇、鱼与月亮等; 而治水 之神大禹是人们耳熟能详的, 殊不知女娲也是理水之神,
女娲以黄土造人的神话和在汉代作为水神、雨神的信仰: 雨不雯, 祭女娲。然而还有些水神不在此两类范围之列, 例如湘妃、屈原、伍子胥、李二郎（李冰之子）、杨二郎 (杨戙)、许真君 (许逊) 等。这些本人就把它分为道教 之神和民间信仰之神, 接下来要谈到的杨泗将军就是属于 真实历史人物神圣化成为水神, 是桃源县的民间信仰之神。

\section{2. 杨泗将军水神形象的衍变过程}

沅水航道从贵州到洞庭湖上千公里, 山高水险, 船工 排工在心理上需要水神保护。一般来说, “水神的“显圣” 多发于堵塞黄运决口或治理水患之时, 河工告竣或水患平 息之后, 官员便会奏报水神“显圣”事件, 祈求皇帝赦命祭 神或官员与地方民众祀神。”[13]暴雨、洪涝历来是桃源县 突出的气候灾害, 部分乡镇, 沅水穿境而过, 尤其在枯水 季节, 沅江水面只低于其所属区域的地面十几米甚至几米 而已。这是水神信仰的兴起最基本的原因。

对于水神杨泗将军的信仰在长江上中下游流传甚广, 遍布南方, 大概有十多个不同的版本。例如, “金井河流 到湖南长沙东乡镇殷家坳, 河上有一座小小的石桥, 名叫 神童桥, 这地方是著者的故乡, 便也是一位大神的生地, 据长沙县志, 这大神是宋代降生, 据乡间父老传言, 这大 神的诞辰是戊申年的六月六日, 这便是二十六代天师奏封 英烈正直威猛将军的杨将军; 在故乡的人们口里, 或称为 杨四将军, 或称为四圣王爷, 或称为平浪王爷。”[14]黄芝 岗先生以自己故乡的杨泗将军作为贯穿全书的主线, 开篇 就讲述杨泗将军大战無義龙的神话故事。又如谷城庙滩: “在江边修盖了船家供奉的“杨泗爷”庙, 因庙建在江边的 沙滩上而得名庙滩”。[15]而根据笔者去年2018年冬亲自走 访沅水下游——常德市以及下属的几个县城。了解到这里 的桃源县所供奉的杨泗将军信仰则是与南宋农民起义领 袖杨么联系在了一起, 通过查找书籍资料来到汉寿县寻找 杨泗将军的踪迹，据“杨么的民间故事”传承人刘子英老先 生考证, 杨么于公元 1108 年出生于龙阳县阳湖口, 杨么本 名为杨太, 因在兄弟中排居最小, 位居第四, 被乡里称呼 为杨幺。在南宋建炎四年二月二十一日, 常德县钟相杨么 举兵起义, 高举“等贵贱、均贫富”义旗, 以龙阳县为根据 地遥相呼应, 进行夺取土地的伟大斗争, 建立“陆耕水战” 的革命耕战体制和农民革命政权。帐下拥有近万名将士, 因其善于水战, 故被民众称为“杨泗将军”、“杨泗菩萨”等 称号。公元 1135 年杨幺在与宋军交战潜水突围时被岳飞部 将牛臬俘获, 他宁死不屈, 岳飞“香其首级, 函送都督行 府告捷，奏闻朝廷”，便留下杨么“赴水死”的传说。

杨幺战死后就归葬于洞庭湖畔的新兴乡祝家岗村风 井杨家坟园, 为防止官府挖掘百姓当时建造了几十座假墓, 现仍有几座杨幺墓, 但只有一座是真墓, 至今岳阳、安乡、 华容、常德县社木铺和湖北传说的杨幺墓都只能是纪念性 假墓。基于民众对含冤而死的爱国英雄的追思怀念与补偿 心理, 在桃源县桃花源建庙立祠祭拜杨泗将军, 同时也表 达了一种民族情绪的投影反射。 


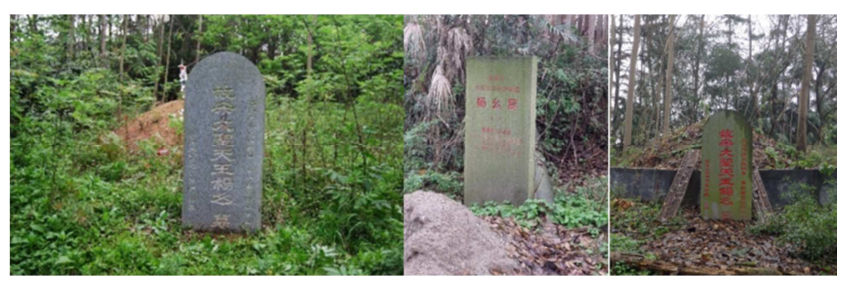

图1 杨幺墓。

打神庙

（渔歌） 汉寿县

城隍庙, 土地庙, 哄我年年把香烧。

赐茶茶不灵, 赐符符无效。

肚皮巴背脊，冬披布筋条。

入了法, 把反造, 八合老米肚鼓包。

城隍丢茅则, 土地当柴烧。

庙柱系战马，神座放甲袍。[16]

等等这些当地的民间歌谣控诉了自古以来人们所迷 信、所崇拜的神并不能实现他们安居乐业的愿望, 而美好 的生活要靠斗争争取而来。

\section{3. 水神信仰活动与圣域营造的象征意义}

在封建社会, 每当出现水灾旱灾人们不自觉地就会 想到一个较好的解决办法——祭拜水神, 以祈求神仙灵 力的庇佑。恩格斯说过: “最初的宗教表现是反映自然 现象、季节更换等等的庆祝活动。一个民族或部落生活 于其中的特定自然条件和自然产物都被搬进了它的宗 教里。”[17]水神庙祠有它自身的内在逻辑性, 而关乎于
人们的宗教信仰、文化取向、宇宙观念、艺术旨趣等精 神现象与它却有着紧密相关的联系, 并以自身特有的空 间、形式、结构化的方式来表达着、展示着其存在的意 义。

\section{1. 祭祀水神的活动}

“在传统中国，民间水神祭祀本来就作为一种生活习 俗、一种宗教文化, 甚至是一种制度, 渗透于地方社会之 中......”[18]在沅水下游的常德市对杨泗将军水神的信仰 不仅仅是满足人们的精神需求, 还已形成固定的祭祀仪式、 香社组织以及庙会。据《常德地区志》记载: “六月六日 为杨泗菩萨诞辰。船业、排筏业等举行祭招。首先请道士 念经, 然后将杨泗神像抬出巡街驱瘟, 敬香礼拜、祈求保 佑。回殿后举行盛大仪式, 凡入会者都要跍拜行礼。仪式 毕, 举行宴饮。早上, 将杨泗神像从河边庙中抬出, 沿街 各户放鞭炮、焚香、烧纸、祭以三牲, 有的献钱钞以酬神。 前一天晚上, 巫师向杨泗将军问卦, 占卜当年雨水, 年成, 瘟疫等情况。当杨泗将军神像回殿后, 巫师即在神前公布 占卜的结果。此时, 远近群众聚集, 倾听巫师讲述。今此 俗已废。”

常德市武陵区志中记载“清代和民国时期, 县境工商 各业还有敬祀各自祖师的习俗, 新中国成立后, 此俗亦 止。”见下图。[19]“从各方志的记载来看, 修建祠庙者来 自社会各个阶层: 否石山洞庭庙由朝廷敕建, 椰州柳候 祠由当地官绅、百姓捐资合建; 来阳县的杨泗庙则是由 船行倡建。”[20]也可以看出杨泗神信仰在民众中的影响 力。

表1 清代和民国时期各行业敬祀先师表（部分）。

\begin{tabular}{|c|c|c|c|c|c|c|c|}
\hline 行业 & 祖师 & 祭祀日期 & 聚集祀庙 & 行业 & 祖师 & 祭祀日期 & 聚集祀庙 \\
\hline 医药 & 孙思㴞 & & 药王宫 & 织布 & 黄道婆 & & \\
\hline 生药 & 神农 & & 后稷宫 & 丝线养蚕 & 嫘祖 & & \\
\hline 酿酒 & 杜康 & & & 腊味 & 宗泽 & & \\
\hline 纸张 & 蔡伦 & & 蔡候祀 & 说书 & 柳敬亭 & & \\
\hline 线业 & 梅葛 & & 葛仙公 & 占卜 & 鬼谷子 & & \\
\hline 印刷 & 毕升 & & & 看相 & 柳庄 & & \\
\hline 铸铁业 & 太上老君 & & 老君堂 & 草鞋 & 刘备 & & \\
\hline 靴鞋 & 孙膑 & 七月十五 & 孙祖庙 & 牌筏 & 杨泗将军 & 六月初四 & 杨泗庙 \\
\hline 成衣 & 轩辕 & & 轩辕宫 & 䇝缆 & 杨泗将军 & & 杨泗庙 \\
\hline 船业 & 杨泗将军 & 六月初四 & 杨泗庙 & 茶叶 & 陆羽 & & \\
\hline
\end{tabular}

当然各地祭祀的时间有所差别, 在长沙县六月初六这 天, 传说是杨泗将军的生辰, 当天在长沙县各埠杨泗庙都 举办盛大祭祀活动与三天的庙会。每条船上均摆上供果盘 子, 插上供香, 把盘着的一条小青蛇供在最上面的神案上, 传说小青蛇是杨泗将军的化身, 每年如此。牌筏、船工、 纸帮等但凡只要是以水为生活来源的行业都会相约集资, 请来戏班在神庙里唱戏设宴感谢杨泗将军的庇佑, 如是等 等, 有些习俗今天又重新开始风行起来。湖南杨泗将军的 信仰也传到了湖北、四川、陕西等临水的地区, 这样的信 仰能够使他们获得心灵上的抚慰并激发生存的力量, 由此 表达了这些以水为生的民众对山川河流、对大自然的热爱 与敬畏之情。

\section{2. 杨泗将军水神庙祠的营造}

“与防洪工程相匹配的, 是祠庙系统的建设。”[21]桃 源古有“扼滇黔咽喉”之说，《嘉庆・常德府志》“常德在古 中国, 皆西通巴蜀, 缘栈道八峡, 其水甚辟（疏通）也, 汉以后其道始湮 (阻塞) ”。这也就是说汉以后桃源沅江 水道是通往云贵的唯一通道, 不仅重要且又险要。在陆路 交通不发达的情况下, 就只有走这条水道。把滇黔和辰、 沅的物资调往京都、武汉等地就是走这条水道。又因桃源 地势低洼, 地域狭小, 每每被洪水所淹。传说古时有位少 年名黄闻, 由于他勇斗鱼怪, 最后舍身化岩镇妖魔, 故称 为黄闻山。后来相传沅江频发水患, 疑妖作怪, 建水府阁 
供奉水神杨泗将军以镇之。“......洞庭湖杨泗将军信仰经 历了一个漫长的演变过程: 杨泗将军斩蕉龙传说, 是晋以 后移植李冰蜀郡治水、江西许逊斩蛟神话传说形成的, 南 宋以后杨泗将军传说在洞庭湖区的流传过程中, 又整合了 湖区有广泛影响的农民起义领袖杨么的事迹, 不仅完成了 其在地化的进程, 同时也使得本为庇佑洞庭湖区百姓的杨 么崇拜发生转型, 成为民众信仰的水神杨泗将军信 仰。”[22]水府图位于沅江急流拐弯处且船只事故多, 所以 在此黄闻山山头面向沅江而建, 暗喻杨泗将军俯瞰并守护 沅江过往船只。据说从此以后沅江风平浪静, 一帆风顺。

“意象, 出自《周易》'圣人立意以尽象”, 这里古人所 指的是卦象而非艺术形象, 但此“意”此“象”却为中国传统 艺术打开了通往意境的道路, 并为当代的景观设计师指明 了“意”——精神、情感、审美与“象”——物象、艺术形象、 景观构成之间的关系。”[23]水府阁建造是在清朝光绪年间, 核心是象征体系的营造, 是自然景观与人文景观的高度融 合。由于木质结构在1962年垮塌, 1992年有位中华奇人侯 希贵先生看了这块风水宝地后，热心捐款进行恢复。“桃 源的山是群峰拱列, 桃源的水是玉带环流。无论那一座山 总有一条碧流蜿蜒相伴。可谓有刚有柔, 刚柔相 济......”[24]传统风水认为, 此地是“玉带缠腰”, 有天然的 “水陆太极图”在此形成较好的气场, 并且之前说到过水府 阁正好落在桃源山七斗峰的文昌星座上。

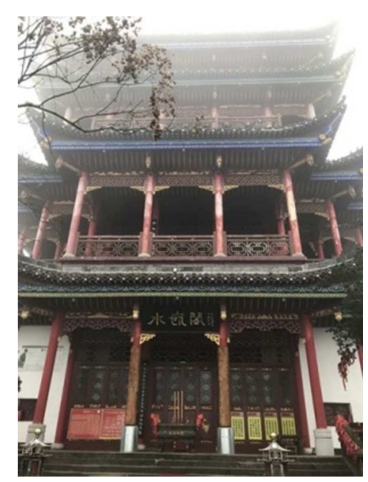

图2 水府阁。

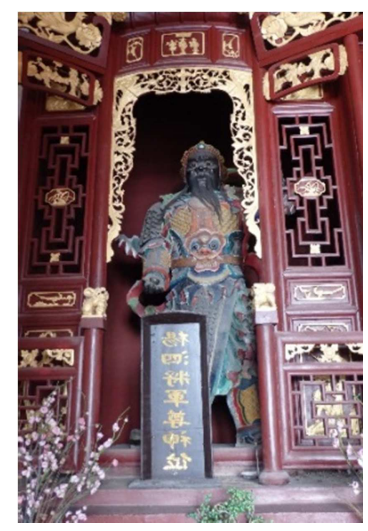

图3 杨泗水神神位。

\section{3. 从桃川万寿宫到水府阁}

“万寿宫是道教和民间信仰融合交汇之地”[25]明嘉靖 《常德府志》记载: “桃川宫, 晋人建”。“始建于晋太康
一年至东晋元熙一年 (280-419)，隋大业年间（605-618） 被毁, 唐代重建, 原名“桃源观”, “禁山开秘宇”, “禅门接 紫霞”, 这里形成了自沅水边至桃花山的巨大建筑群, 到 元惠宗时（1333-1368）毁于战乱。明、清两代, 桃花源 的建筑移至桃花山, 以秦人洞侧之大士阁 (今桃花观) 为 主体, 时兴时废。清光绪年间, 知县余良栋任内沿桃花山 配置亭阁, 至民国末年衰败......。”[26]桃川万寿宫位于沅 水下游南岸水溪汇入处, 就是蜚声中外的风景名胜区一 桃花源。桃川万寿宫原名“桃源观”, 分上、中、下三宫。 光落地的柱头就有 1330 根, 气势宏伟, 公元 1112 年, 宋徽 宗御笔钦赐“桃川万寿宫”骗额, 是江南著名的皇家道观, 可惜在元末毁于兵火, 距今至少已有一千六百年。现今是 湖南省道教协会在遗址上重建了桃川宫的中宫、下宫和玉 皇殿、东西行宫、财神殿、钟鼓楼、牌楼等建筑。

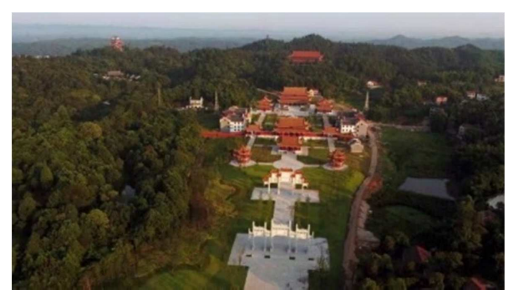

图4 桃川万寿宫鸟瞰图（1）。

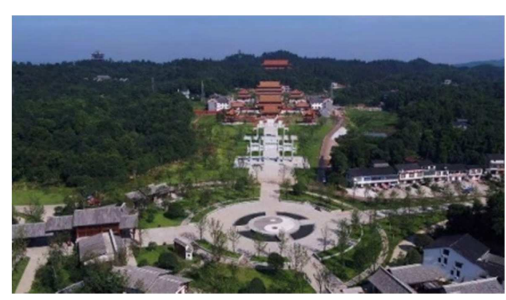

图5 桃川万寿宫鸟瞰图（2）。

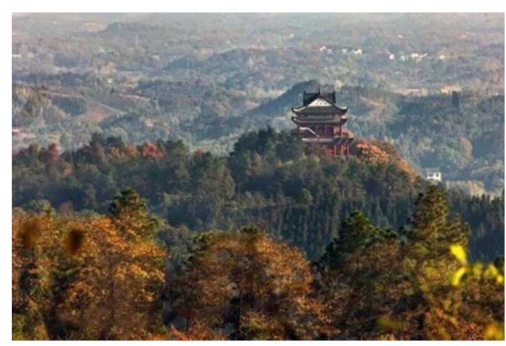

图6 文昌星座。

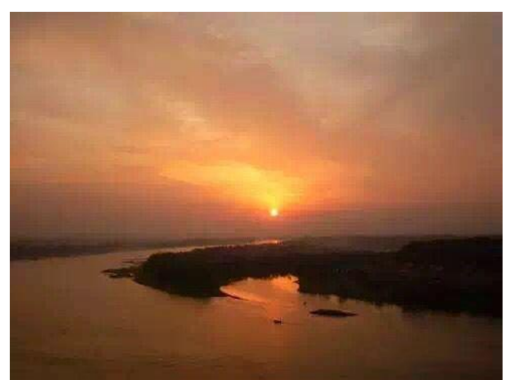

图7 水陆阴阳太极图。

“宗教建筑是宗教信徒精神寄托之所在, 是净化心灵、 与神灵联通与对话的场所，带有神圣而神秘的色彩。”[27] 
说水府阁它也是桃川宫的一个殿，始建于明末，原名黄闻 阁, 高踞桃花源镇黄闻山之巅, 有“潚湘一阁”之称誉。原 来是三层砖木结构, 清初被毁掉。光绪年间重建为重檐歇 山顶四层楼阁, 高36.3米, 与高举阁南北相对。下瞰桃川, 东望洞庭, 西顾壸头, 江天辽阔。这里传说桃源山有七斗 峰, 是北斗七星下凡, 水府阁就恰好落在第四星文昌星座 上, 正对沅江与白鳞舟水陆阴阳太极图, 自然玄妙, 天机 演化, 仙山秀水, 人杰地灵, 所以水府阁成为了道教神仙 阁, 一阁的神仙演绎, 一阁的香火传奇, 这里的“渔村夕 照”即“三日同辉”，是古潇湘八景之一，为什么会出现如 此景观呢? 原因在于东西两处水面有高有低, 在每年十一 月下旬四点半到五点左右, 在阳光的照射下, 生成两个太 阳的倒影, 这种奇观是极难看到, 可遇而不可求。

\section{4. 结论}

“任何一个神庙都有着不同的象征功能, 这决定了它 的造型和表达性。”[28]杨泗将军水神庙也是如此, 作为全 国第三十五洞天、第四十六福地的桃源县, 而洞天福地与 道教的风水学关系极为密切, “背山面水、负阴抱阳”是理 想风水模式结构的典型特征, “左青龙、右白虎、前朱雀、 后玄武”是“风水佳穴”式布局的标准。”[29]“对应到具体方 位, 则是北要有连绵的高山作为屏障 (玄武), 东西要有 高高低低的众山体重重围护（青龙、白虎）, 南面山脉止 落之处要有水脉相依 (朱雀), 穴场地势平坦, 与周围环 境相对独立和隔离, 周边通过狭小的豁口和走廊与外界相 连通, 从而形成最佳的风水格局。”[30]水有着两面性, “体 现在水生万物、水主生育、拔除不详, 以及水灾、水患等 正负两方面的影响。”[31]对于水神信仰, 象征着对水拥有 神秘力量的神的一种崇拜, 在农业社会则是对自然的一种 崇拜。

“环境治理不能只靠刚性的科技力量, 更应该重视软 性的文化力量......”[32]所以, 水神崇拜与圣域营造是一种 对历史圣域的保护和对未来生态保护的总体规划, 沅水发 于贵州省, 贯穿湖南省境内, 被称为湖南省第二大河流。 当前, 我国正在积极推动长江经济带建设, 保护沅水流域 的水环境也正成为人们高度重视的课题, 本文选取的是沅 水下游的桃源县，所秉承的是“敬畏江河、与水共生”的流 域生态环境保护理念。

\section{参考文献}

[1] 孟莹、张冠增: 《乡村空间营造的逻辑——基于文化与社 会空间理论视角的分析》，城市规划，2018.06期。

[2] 谢纳: 《空间生产与文化表征一空间转向视阈中的文学 研究》【M】.北京：中国人民大学出版社，2010。

[3] [挪]克里斯蒂安・诺伯格一舒尔茨《西方建筑的意义》, 中 国建筑工业出版社，2016.07版，第5页。

[4] 要宇, 高金峑, 韩卫成, 《山西道教建筑空间营造技术研 究》, 科学技术哲学研究, 2018.02, 第1期。
[5] 付广华, 《壮族传统水文化与当代生态文明建设》, 广西 民族研究，2010年03期。

[6] 李俊涛, 《道家丹道养生图像语法对现代生态旅游规划设 计的启示》，文艺研究，2013年第4期。

[7] 程宇昌, 《鄱阳湖渔民水神信仰与晏公庙探析》, 江西社 会科学，2016年第10期。

[8] 陈曦, 《宋代荆湖北路的水神信仰与生态环境》, 湖北社 会科学, 2009年第9期。

[9] 刘锡诚: 《水与水神》, 学苑出版社, 1994年版第1-2页。

[10] 向柏松, 《道教与水崇拜》, 中南民族学院学报（哲学社 会科学版），1999年第1期。

[11] [明]周景一撰: 《山洋指迷》, 转引自练力华编著: 《中 国环境地理学》 (上), 北京: 中央编译出版社, 2014年, 第24页。

[12] 李裴, 《环境美学视域下的道教崇水渊源》, 宗教学研究, 2019.02期。

[13] 胡梦飞, 《明清时期苏北地区水神信仰的历史考察—— 运河沿线区域为中心》, 江苏社会科学，2013.03期。

[14] 黄芝岗: 《中国的水神》, 上海文艺出版社, 1988年版第1 页。

[15] 谷城县地名领导小组办公室编: 《湖北省谷城县地名志》, 内部资料，1985年。

[16] 曹嬿婉: 《中国民间歌谣集成湖南卷 汉寿县资料本》, 汉 寿县民间文学集成编委会，1987年版第32页。

[17] 恩格斯.致马克思 $[\mathrm{A}]$.马克思恩格斯全集第27卷 [M]. 北京: 人民出版社，1972。

[18] 李峻杰, 《逝去的水神世界——清代山西水神祭祀的类型 与地域分布》, 民俗研究, 2013年02期。

[19] 常德市武陵区地方志编纂委员会, 《常德市武陵区志》, （1988-2005），湖南人民出版社，第581页。

[20] 王元林、李娟, 《历史上湖南湘江流域水神信仰初探》, 求索, 2009.01期。

[21］周亚、岳云霄, 《治水兴城: 宋代以来太原城的生命史一 以汾河水患的防治为中心》, 福建论坛 (人文社会科学版), 2018年04期。

[22] 李琳, 《洞庭湖水神信仰研究》, 湖南人民出版社, 2012 年，第83页。

[23] 从昕、郭敏、陆婧、张清海, 《传统村落景观意向营造中 空间形态的解析》, 南京艺术学院学报 (美术与设计), 2018.05期。

[24] 刘有恒: 《桃源古今漫谈》, 海南出版社, 2006年版, 第 35页。

[25] 万建中, 万寿宫古庙会的生存基因与传承机制【 $\mathrm{J} 】$, 地方 文化研究, 2016（5）：17。 
[26] 桃源县地方志编纂委员会: 《桃源县志》, 湖南出版社, 1995年版，第501页。

[27] 丁菁, 《我国宗教建筑所有权主体与权能研究》, 浙江师 范大学学报 (社会科学版) 2016.04期。

[28] F- 克劳斯《帕埃斯图姆》, 关于神庙的全面讨论, (F.Krauss, Paestum, 柏林, 1941年。

[29] 苗诗麟、金荷仙、王欣, 《江南洞天福地景观布局特征》, 中国园林，2017.05期。

[30] 李晟, 《仙境信仰研究》 [M].成都：巴蜀书社, 2010。

[31] 张帆, 《明清戏曲与水神信仰》, 戏剧 (中央戏剧学院学 报），2018年02期。
[32] 张群辉, 《云南少数民族传统水信仰的生态功能与传承教 育》，玉溪师范学院学报，2018年07期。

\section{作者简介}

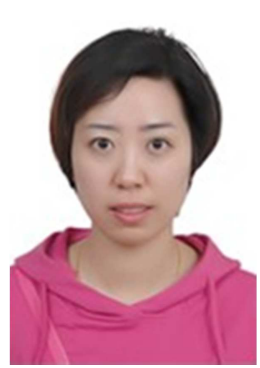

郑丹丹 (1980—) 一, 女, 湖北鄂州人, 中国地质大学艺术与传媒学院讲师。 博士研究方向: 环境规划与设计。 